\title{
TEMPERATURAS SUPERFICIAIS DE TELHAS E SUA RELAÇÃO COM O AMBIENTE TÉRMICO
}

\section{CARLOS A. DE P. SAMPAIO ${ }^{1}$, CÉLIO O. CARDOSO ${ }^{2}$, GEOVANI P. DE SOUZA ${ }^{3}$}

RESUMO: Este trabalho teve como objetivo a análise de temperaturas de telhas de barro, de fibrocimento com pintura branca na face superior e de aço zincado e sua relação com o ambiente térmico, quantificando também os Índices de Temperatura e Umidade (ITU), de Temperatura de Globo e Umidade (ITGU) e Carga Térmica de Radiação (CTR). As análises foram realizadas em modelos de edificações e na área não sombreada. Os resultados mostraram que as telhas cerâmicas e de fibrocimento apresentaram comportamentos térmicos semelhantes, sendo que a opção pela telha de fibrocimento de $5 \mathrm{~mm}$, pintada de branca na sua face superior, é vantajosa economicamente. As telhas metálicas superaram os $53{ }^{\circ} \mathrm{C}$ na sua superfície e foram piores no conforto térmico comparado com as outras telhas. O ITGU foi superior na indicação do conforto térmico em relação ao ITU, principalmente no verão. Houve redução significativa da CTR pelas telhas em relação à área não sombreada.

PALAVRAS-CHAVE: telhas, fatores ambientais, conforto térmico, índices.

\section{SUPERFICIAL TEMPERATURES OF TILES AND THE RELATION WITH THERMAL ENVIRONMENT}

\begin{abstract}
The objective of this study was the analysis of temperatures of clay tiles, galvanized steel tiles and fiber-cement tiles with white painting on the roof and his relation with the thermal environment, in winter and summer conditions. The experiment was carried out in models of constructions quantifying the internal and extern temperatures from the tiles (TS), Temperature and humidity index (THI), Black Globe and Humidity (BGHI) and Thermal Load of Radiation (TLR) were employed for the characterization of the thermal environmental. The measured were performed inside and outside the housing. The results showed that the ceramic tiles and the fibercement tiles presented similar thermal behaviors and the choice of fiber-cement tiles of $5 \mathrm{~mm}$ with white painting on the roof is economically advantageous. The metal tiles were the ones that most heated up surpassing $53^{\circ} \mathrm{C}$ in his surface and the worst regarding to the thermal comfort compared with the other tiles. The THI was not accurate for determining thermal comfort under tropical conditions. There was significant reduction of RTL by the tiles to the not shaded area.
\end{abstract}

KEYWORDS: tiles, environmental factors, thermal comfort, indexes.

\section{INTRODUÇÃO}

O telhado é o elemento construtivo mais importante de uma edificação, e tal fato deve-se à grande área de interceptação de radiação e que, em regiões tropicais, a escolha adequada da telha torna-se fator principal para o conforto térmico.

SANTOS et al. (2002) descrevem que os materiais de cobertura utilizados nas edificações para animais podem não ser simultaneamente eficientes para condições de verão e de inverno. Essas condições geram perdas ou gastos excessivos e que uma das maneiras de contornar ou amenizar este grande problema é com procedimentos construtivos mais corretos.

\footnotetext{
${ }^{1}$ Eng$^{\mathrm{o}}$ Agrícola, Prof. Associado, Centro de Ciências Agroveterinárias, CAV/UDESC, Lages - SC, a2caps@ cav.udesc.br.

${ }^{2}$ Eng ${ }^{0}$ Agrônomo, Prof. Associado, Centro de Ciências Agroveterinárias, CAV/ UDESC, Lages - SC.

${ }^{3}$ Graduando em Agronomia, Universidade do Estado de Santa Catarina, Bolsista PROBIC/UDESC.

Recebido pelo Conselho Editorial em: 25-8-2010

Aprovado pelo Conselho Editorial em: 6-2-2011
} 
TEIXEIRA (1996) cita que o limite mínimo do ITGU para que os frangos de corte não sofram de estresse por frio seja de 78,6 para pintos, em sua primeira semana de vida, de 67,4 para pintos, em sua segunda semana de vida, e de 65,0 para aves entre a terceira e a sexta semana de vida.

TINÔCO (1988), em experimento com frangos de corte nas condições de verão, verificou que valores de ITGU superiores a 75,0 causam desconforto nas aves acima de quinze dias de vida, com agravamento do estresse na medida em que as aves se desenvolvem.

Com relação a ruminantes, principalmente das raças bovinas, existe grande variação nos valores das temperaturas críticas superior e inferior, como também nos valores dos índices de conforto. CAMPOS et al. (2002) propuseram um limite máximo de 75 para o ITU, visando ao conforto térmico do rebanho leiteiro da raça holandesa, e observaram que, para valores de ITU de 70 ou menos, nenhum desconforto térmico para vacas leiteiras ocorre e, para valores de 75 ou mais, a produção de leite e a ingestão de alimentos ficam seriamente prejudicadas. Descreve ainda que bovinos de todas as idades mostraram algum sinal de desconforto térmico com ITU igual ou superior a 78, tornando-se agudo com o aumento no valor deste índice.

SANTOS et al. (2002) realizaram estudos em modelos de galpões avícolas com cobertura de telhas de barro e alumínio com duas alturas de pé-direito, em condições de inverno, e concluíram que as coberturas, nas horas de frio intenso, tiveram os valores de ITGU abaixo da zona de conforto térmico, sugerindo melhor isolamento das instalações durante este período.

Trabalho realizado por ROSA (1984) foram obtidos, às 14 horas, em dia típico de céu limpo com $12 \mathrm{~h} 30$ de insolação, valores de CTR de 498,3 $\mathrm{W} \mathrm{m}^{-2}, 515,0 \mathrm{~W} \mathrm{~m}^{-2}$ e 498,0 $\mathrm{W} \mathrm{m}^{-2}$ sob telhas de barro tipo francesas, de cimento-amianto e de alumínio, respectivamente.

MORAES et al. (1999) realizaram estudos em modelos de galpões com cobertura de telhas de cimento-amianto e encontraram valores de ITGU entre 75,5 a 83,2 nas horas mais quentes e de CTR entre $455,2 \mathrm{~W} \mathrm{~m}^{-2}$ e $504,0 \mathrm{~W} \mathrm{~m}^{-2}$.

CONCEIÇÃO et al. (2008) compararam telhas convencionais e outras em protótipos de galpões avícolas para as condições de verão e encontraram os seguintes valores médios para telhas de cimento-amianto pintadas com tinta reflexiva e telhas cerâmicas, respectivamente: ITU (71,973 e 72,294), ITGU (71,876 e 73,707), CTR (449,174 $\mathrm{W} \mathrm{m}^{-2}$ e 477,740 $\mathrm{W} \mathrm{m}^{-2}$ ).

A maioria dos trabalhos relacionados aos materiais de cobertura para as condições brasileiras avalia o aquecimento térmico do ambiente e soluções quando for o caso, o que é coerente, pois o País apresenta, na média, verões quentes ou muito quentes, e grande parte dos animais sofre de estresse pelo calor. Entretanto, o País apresenta também regiões de climas adversos e frio intenso ou parte destas condições, e esta avaliação pode não ser correta, devendo respeitar as características climáticas pontuais dessas regiões.

Pelo exposto, este trabalho teve por objetivos avaliar as temperaturas superficiais externa e interna de telhas de barro, de fibrocimento com pintura branca na face superior e de aço galvanizado, e verificar a relação com o conforto térmico, com base nas temperaturas superficiais (TS) e nos índices ITU, ITGU e CTR, em condições de verão e de inverno.

\section{MATERIAL E MÉTODOS}

Este trabalho foi realizado na Área de Construções e Ambiência do Centro de Ciências Agroveterinárias, Lages - SC, durante o verão e inverno de 2008. O clima da região, segundo classificação de Köeppen, é Cfa (clima temperado quente; temperatura média do mês mais frio está entre 18 e $-3{ }^{\circ} \mathrm{C}$ - mesotérmico; a temperatura média do mês mais quente é superior a $22{ }^{\circ} \mathrm{C}$; ausência de estação seca; constantemente úmido, com chuva ou neve em todos os meses). A cidade está localizada a uma latitude de $27^{\circ} 49^{\prime}$ sul, longitude de $50^{\circ} 20^{\prime}$ oeste e altitude de $940 \mathrm{~m}$.

Para a execução deste experimento, foram construídos três modelos de edificações em escala distorcida, nas dimensões de 1,40 $\mathrm{m}$ de largura, 3,00 $\mathrm{m}$ de comprimento, 1,50 $\mathrm{m}$ de pé-direito, ou 
seja, escala reduzida de 1:10, nas dimensões horizontais, e de 1:2, nas dimensões verticais, constituindo os tratamentos. Os modelos foram construídos em terreno plano, nivelado e gramado, livre de sombreamento e distanciados 4,0 m entre si. As paredes laterais eram formadas por tijolos cerâmicos chapiscados.

A estrutura do telhado foi em madeira de pinheiro, e o material de cobertura usado para comparação foi o seguinte: telha de barro tipo francesa vermelha; telha de fibrocimento de 5,0 mm de espessura, com pintura branca na face superior, e telha de aço galvanizado de 0,65 mm de espessura, tendo a área não sombreada como testemunha. As coberturas tiveram inclinação de $30 \%$. As cumeeiras dos modelos reduzidos foram orientadas na direção leste-oeste verdadeiro.

As temperaturas superficiais interna e externa das telhas foram obtidas com uso de termômetro de infravermelho com mira laser. As temperaturas de globo, umidade do ar e vento foram obtidas com termômetro de globo negro, psicrômetro giratório e anemômetro digital de hélice, respectivamente. As medidas foram feitas sobre o centro do piso, a uma altura de 0,75 m, correspondendo ao centro geométrico do galpão.

Os dados foram obtidos em dez dias típicos de verão e inverno, das 8 às 18 horas, em intervalos horários. Os índices medidos foram ITU (THOM, 1958); ITGU (BUFFINGTON et al., 1981) e CTR (BOND \& KELLY, 1955).

O delineamento utilizado foi em blocos casualizados (horários) para a comparação das temperaturas superficiais e dos índices de conforto térmico, tendo os dias como repetição e a área não sombreada como testemunha. Para a análise de variância, foi empregado o teste "F", e as médias, comparadas pelo teste de Tukey, a $5 \%$ de probabilidade.

\section{RESULTADOS E DISCUSSÃO}

Na Tabela 1, são apresentados os resultados do teste de Tukey para as temperaturas superficiais de telhas para as condições de verão e de inverno.

TABELA 1. Valores médios de temperaturas superficiais externas $\left(\mathrm{TS}_{\mathrm{ext}}\right)$ e internas $\left(\mathrm{TS}_{\text {int. }}\right)$ de telhas cerâmicas $\left(\mathrm{T}_{\text {cer. }}\right)$, fibrocimento $\left(\mathrm{T}_{\text {cer. }}\right)$ e metálicas $\left(\mathrm{T}_{\text {met. }}\right)$, nas condições de verão $^{\text {(sup) }}$ e de inverno ${ }^{\text {(inf) }}$. Mean values of external surface temperatures $\left(\mathbf{S T}_{\text {ext. }}\right.$ ) and internal $\left(\mathbf{S} \mathbf{T}_{\text {int. }}\right)$ of ceramic tiles $\left(\mathbf{T}_{\text {cer. }}\right)$, cement tiles $\left(\mathbf{T}_{\text {fc. }}\right)$ and metallic tiles $\left(T_{\text {met. }}\right)$ under summer ${ }^{\text {(sup) }}$ and winter ${ }^{(\text {inf) }}$ conditions.

\begin{tabular}{crcrrrr}
\hline \multirow{2}{*}{ Horas } & \multicolumn{3}{c}{$\mathrm{TS}_{\text {ext. }}$} & \multicolumn{3}{c}{$\mathrm{TS}_{\text {int. }}$} \\
\cline { 2 - 7 } & $\mathrm{T}_{\text {cer }}$ & $\mathrm{T}_{\mathrm{fc}}$ & $\mathrm{T}_{\text {met }}$ & \multicolumn{1}{c}{$\mathrm{T}_{\text {cer }}$} & \multicolumn{1}{c}{$\mathrm{T}_{\mathrm{fc}}$} & $\mathrm{T}_{\text {met }}$ \\
\hline \multirow{2}{*}{$8: 00$} & $24,00 \mathrm{~b}$ & $26,20 \mathrm{~b}$ & $34,02 \mathrm{a}$ & $21,54 \mathrm{~b}$ & $23,78 \mathrm{~b}$ & $30,56 \mathrm{a}$ \\
& $8,91 \mathrm{~b}$ & $11,19 \mathrm{ab}$ & $13,80 \mathrm{a}$ & $9,01 \mathrm{~b}$ & $9,64 \mathrm{~b}$ & $14,09 \mathrm{a}$ \\
\hline \multirow{2}{*}{$10: 00$} & $31,88 \mathrm{~b}$ & $35,15 \mathrm{~b}$ & $46,85 \mathrm{a}$ & $28,27 \mathrm{~b}$ & $30,18 \mathrm{~b}$ & $42,70 \mathrm{a}$ \\
& $18,39 \mathrm{~b}$ & $20,47 \mathrm{~b}$ & $30,90 \mathrm{a}$ & $16,57 \mathrm{~b}$ & $18,93 \mathrm{~b}$ & $31,30 \mathrm{a}$ \\
\hline \multirow{2}{*}{$12: 00$} & $35,22 \mathrm{~b}$ & $34,95 \mathrm{~b}$ & $47,38 \mathrm{a}$ & $32,37 \mathrm{~b}$ & $33,60 \mathrm{~b}$ & $46,07 \mathrm{a}$ \\
& $23,21 \mathrm{~b}$ & $23,62 \mathrm{~b}$ & $35,27 \mathrm{a}$ & $21,78 \mathrm{~b}$ & $22,54 \mathrm{~b}$ & $35,09 \mathrm{a}$ \\
\hline \multirow{2}{*}{$14: 00$} & $36,70 \mathrm{~b}$ & $36,07 \mathrm{~b}$ & $53,53 \mathrm{a}$ & $31,20 \mathrm{~b}$ & $34,27 \mathrm{~b}$ & $51,55 \mathrm{a}$ \\
& $24,63 \mathrm{~b}$ & $23,79 \mathrm{~b}$ & $36,09 \mathrm{c}$ & $23,04 \mathrm{~b}$ & $23,17 \mathrm{~b}$ & $36,96 \mathrm{a}$ \\
\hline \multirow{2}{*}{$16: 00$} & $34,60 \mathrm{~b}$ & $34,67 \mathrm{~b}$ & $46,87 \mathrm{a}$ & $30,65 \mathrm{~b}$ & $33,27 \mathrm{~b}$ & $44,95 \mathrm{a}$ \\
& $19,16 \mathrm{~b}$ & $20,66 \mathrm{~b}$ & $28,11 \mathrm{a}$ & $18,84 \mathrm{~b}$ & $19,07 \mathrm{~b}$ & $29,22 \mathrm{a}$ \\
\hline \multirow{2}{*}{$18: 00$} & $29,98 \mathrm{~b}$ & $31,35 \mathrm{~b}$ & $36,25 \mathrm{a}$ & $28,20 \mathrm{~b}$ & $29,52 \mathrm{~b}$ & $37,18 \mathrm{a}$ \\
& $12,48 \mathrm{a}$ & $13,29 \mathrm{a}$ & $14,90 \mathrm{a}$ & $14,58 \mathrm{~b}$ & $14,29 \mathrm{~b}$ & $17,24 \mathrm{a}$ \\
\hline
\end{tabular}

Letras iguais na mesma linha não diferem pelo teste Tukey, ao nível de $5 \%$ de probabilidade.

Observando a Tabela 1, não se constatam diferenças estatísticas nas temperaturas superficiais das telhas de barro e de fibrocimento pintadas de branco na face superior, ou seja, estas telhas apresentaram comportamentos térmicos próximos. As telhas metálicas foram mais quentes até $17^{\circ} \mathrm{C}$ 
e $19^{\circ} \mathrm{C}$ no verão, e de $14{ }^{\circ} \mathrm{C}$ e de $16^{\circ} \mathrm{C}$ no inverno, em relação às telhas de barro e de fibrocimento nas superfícies externa e interna, respectivamente, o que traduz que as telhas metálicas possuem características térmicas inadequadas para o conforto térmico, como amortecimento térmico, atraso térmico e condutibilidade térmica. Nota-se ainda que a amplitude térmica das telhas metálicas durante o dia foi até $11^{\circ} \mathrm{C}$ superior em relação às outras telhas, o que é inconveniente, pois os ambientes com essa telha poderão apresentar bolsões de calor e alta desuniformidade de temperatura no seu interior durante o dia.

Na Tabela 2, são apresentados os resultados do teste de Tukey para ITU e ITGU nos ambientes, onde se nota que há diferenças estatísticas para os índices de acordo com as telhas, sendo que a primeira constatação é de que o ITGU é mais sensível para predizer o conforto térmico que o ITU, fato já observado em várias pesquisas de ambiência animal.

TABELA 2. Valores médios de ITU e ITGU para telhas cerâmicas $\left(\mathrm{T}_{\text {cer. }}\right)$, fibrocimento $\left(\mathrm{T}_{\mathrm{fc}}\right)$ e metálicas $\left(\mathrm{T}_{\text {met. }}\right)$ e na área não sombreada $\left(\mathrm{A}_{\text {ext. }}\right)$, nas condições de verão ${ }^{(\sup )} \mathrm{e}$ de inverno $^{(i n f)}$. Mean values of THI and BGHI for ceramic tiles $\left(\mathbf{T}_{\text {cer. }}\right)$, cement tiles $\left(T_{\text {fc. }}\right)$ and metallic tiles $\left(T_{\text {met. }}\right)$ and in the not shaded area $\left(A_{\text {ext. }}\right)$, under summer ${ }^{\text {(sup) }}$ and winter ${ }^{\text {(inf) }}$ conditions.

\begin{tabular}{|c|c|c|c|c|c|c|c|c|}
\hline \multirow{2}{*}{ Horas } & \multicolumn{4}{|c|}{ ITU } & \multicolumn{4}{|c|}{ ITGU } \\
\hline & $\mathrm{T}_{\text {cer. }}$ & $\mathrm{T}_{\mathrm{fc}}$ & $\mathrm{T}_{\text {met. }}$ & $\mathrm{A}_{\text {ext }}$ & $\mathrm{T}_{\text {cer. }}$ & $\mathrm{T}_{\mathrm{fc}}$ & $\mathrm{T}_{\text {met }}$ & $\mathrm{A}_{\text {ext }}$ \\
\hline \multirow{2}{*}{ 8:00 } & $64,4 a$ & $64,2 \mathrm{a}$ & $64,4 a$ & $65,1 \mathrm{~b}$ & $64,4 a$ & $64,2 \mathrm{a}$ & $65,5 a$ & $71,1 \mathrm{~b}$ \\
\hline & $54,7 a$ & $54,7 a$ & $54,6 a$ & $54,3 a$ & $53,5 a$ & $53,6 a$ & $53,5 a$ & $58,8 b$ \\
\hline \multirow{2}{*}{$10: 00$} & $68,1 \mathrm{a}$ & $68,3 a$ & $68,4 a$ & $68,6 a$ & $69,2 b$ & $70,0 \mathrm{a}$ & $71,7 \mathrm{a}$ & $80,6 b$ \\
\hline & $60,8 a$ & $60,8 a$ & $60,8 a$ & $61,0 a$ & $59,8 a$ & $60,1 a$ & $59,1 a$ & $67,9 b$ \\
\hline \multirow{2}{*}{$12: 00$} & $70,3 a$ & $70,6 a$ & $70,7 a$ & $71,2 b$ & $71,3 b$ & $72,1 b$ & $73,9 a$ & $79,4 c$ \\
\hline & $64,7 b$ & $65,0 a$ & $64,9 a b$ & $65,3 c$ & $63,9 a$ & $64,3 a$ & $63,6 a$ & $71,2 b$ \\
\hline \multirow{2}{*}{$14: 00$} & $71,8 \mathrm{a}$ & $72,3 b$ & $72,1 \mathrm{ab}$ & $72,4 b$ & $73,2 b$ & $73,6 b$ & $74,8 \mathrm{a}$ & $80,7 \mathrm{c}$ \\
\hline & $67,5 a$ & $67,6 a$ & $67,7 a$ & $67,8 a$ & $66,7 a$ & $66,8 a$ & $66,0 a$ & $74,0 b$ \\
\hline \multirow{2}{*}{$16: 00$} & $71,7 \mathrm{a}$ & $72,1 b$ & 71,9ab & $71,5 \mathrm{a}$ & $71,9 a$ & $72,8 \mathrm{ab}$ & $73,0 \mathrm{~b}$ & $77,1 \mathrm{c}$ \\
\hline & $67,2 a$ & $67,2 a$ & $67,2 a$ & $66,7 b$ & $71,5 a$ & $71,4 a$ & $71,3 a$ & $70,7 b$ \\
\hline \multirow{2}{*}{$18: 00$} & $70,9 a$ & $71,2 \mathrm{a}$ & $71,1 \mathrm{a}$ & $71,1 \mathrm{a}$ & $70,8 \mathrm{a}$ & $71,1 \mathrm{ab}$ & $72,0 b$ & $76,7 \mathrm{c}$ \\
\hline & $63,5 a$ & $63,5 a$ & $63,5 a$ & $63,1 b$ & $61,7 a$ & $61,6 a$ & $61,4 a$ & $59,5 a$ \\
\hline
\end{tabular}

Letras iguais na mesma linha não diferem pelo teste Tukey, a $5 \%$ de probabilidade.

Os valores de ITGUs com cobertura de fibrocimento ficaram entre 64,2 e 73,5 (verão), e de 54,7 a 67,6 (inverno), inferiores aos encontrados por MORAES et al. (1999) e CONCEIÇÃO et al. (2008), e isso é devido às diferenças climáticas das regiões.

Valores mais altos de ITUs e ITGUs foram observados para telhas metálicas, principalmente nas horas mais quentes. Comparando-se com a área não sombreada, as telhas foram eficientes para melhorar as condições de conforto térmico do ambiente.

Os índices mostraram-se baixos para criação de aves nas idades iniciais, como descrito por TEIXEIRA (1996), e ligeiramente desconfortável para as aves em idades mais avançadas.

O limite máximo de 75 para ITU não foi ultrapassado em nenhum momento, mesmo nas horas mais quentes e também na área não sombreada, mostrando-se adequada para criação de bovinos leiteiros de forma extensiva, como descrito por CAMPOS et al. (2002).

Na Figura 1, mostram-se os valores de ITGU e de ITU em função dos horários de observação para as condições de verão e de inverno, onde se pode observar com maior clareza que o ITGU é mais sensível para predizer o conforto térmico que o ITU. 
Podem-se observar, na área não sombreada, variações de temperatura acompanhando o clima local, enquanto nos modelos há um comportamento térmico mais suave no decorrer do dia, pois a cobertura ameniza as variações e não deixa a flutuação térmica ocorrer de forma mais abrupta.

Verifica-se, para condições de inverno, que o telhado amortece a perda de calor nas horas em que a temperatura começa a decrescer, por volta das 17 horas, amenizando o desconforto pelo frio, situação não verificada na área não sombreada, onde as quedas bruscas de temperatura não são amortecidas, indesejável nas criações de alguns animais de forma extensiva.

Assumindo-se 75 como sendo o valor de ITGU no limite máximo tolerado sem estresse para frangos de corte, com mais de três semanas de idade (TINOCO, 1988), o uso de cobertura permitiu que estivesse dentro da faixa de conforto. Assumindo 75 (CAMPOS et al., 2002) como valor limite de ITU, este limite não foi ultrapassado em nenhum momento, embora nestas épocas do ano, na região, deve-se dar atenção aos limites inferiores de temperatura.
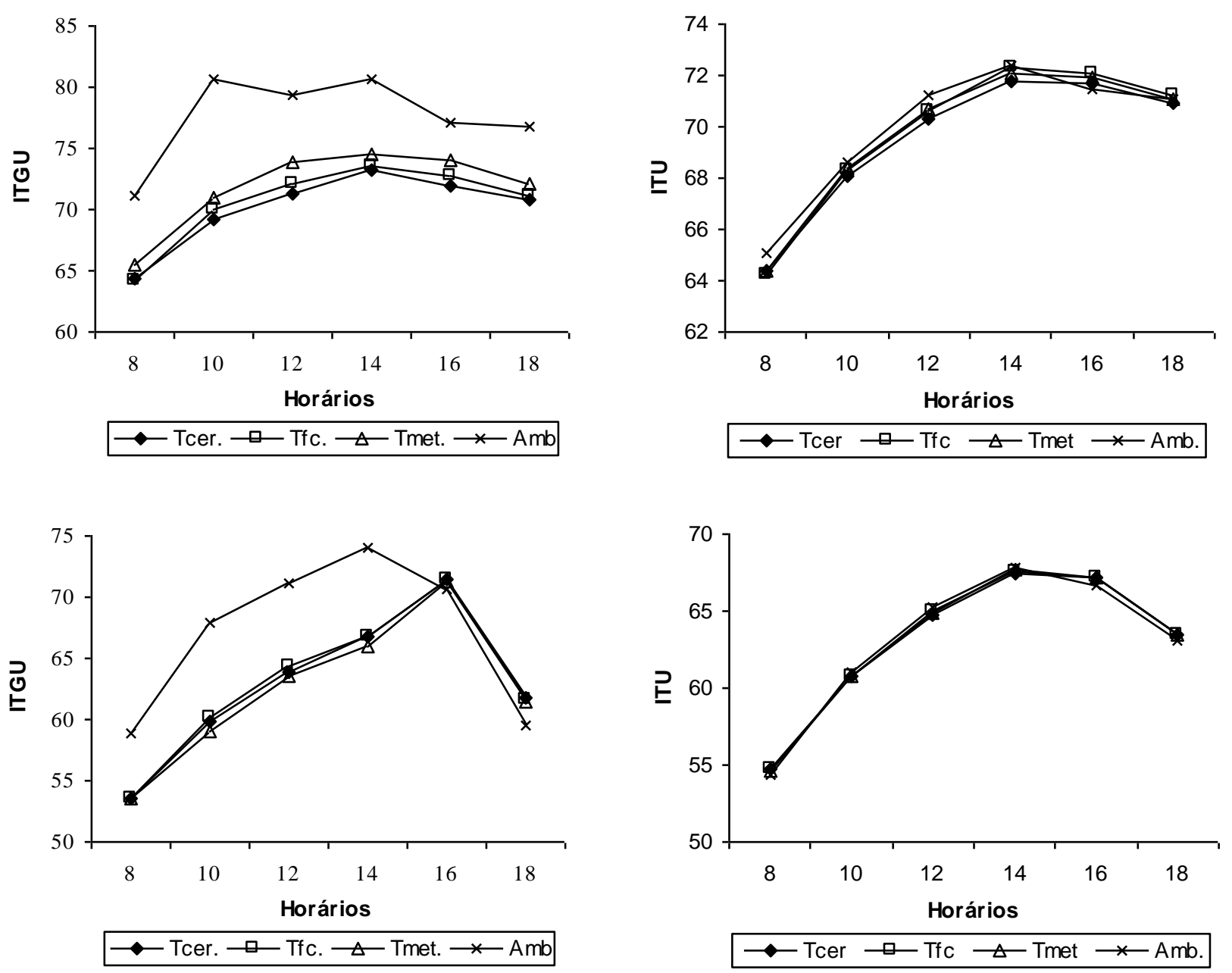

FIGURA 1. Valores médios de ITGU e ITU nos ambientes de telhas cerâmicas ( $\left.\mathrm{T}_{\text {cer. }}\right)$, fibrocimento $\left(\mathrm{T}_{\mathrm{fc}}\right)$, metálicas $\left(\mathrm{T}_{\text {met. }}\right)$ e na área não sombreada $\left(\mathrm{A}_{\mathrm{ext} .}\right)$, nas condições de verão ${ }^{(\mathrm{sup})}$ e de inverno $^{(\mathrm{inf})}$. Mean values of THI and BGHI in the ceramic tile $\left(\mathbf{T}_{\text {cer. }}\right)$, cement tile $\left(T_{\text {fc. }}\right)$ and metallic tile $\left(T_{\text {met. }}\right)$ and in the not shaded area $\left(A_{\text {ext. }}\right)$, under summer ${ }^{\text {(sup) }}$ and winter ${ }^{\text {(inf) }}$ conditions.

Os valores médios da carga térmica de radiação (CTR) para as condições de verão e de inverno são mostrados na Figura 2. 
De início, pode-se verificar que as telhas foram importantes para a redução de CTR quando comparada com a área não sombreada e, à semelhança dos índices ITU e ITGU, os valores de CTRs variaram em maior intensidade entre 12 e 16 horas.

A CTR variou de 406,7 a 479,2 $\mathrm{W} \mathrm{m}^{-2}$, de 405,0 a 480,5 $\mathrm{W} \mathrm{m}^{-2}$ e de 406,2 a 518,3 $\mathrm{W} \mathrm{m}^{-2}$ para telhas cerâmicas, de fibrocimento e metálicas, respectivamente, mostrando que as telhas cerâmicas e de fibrocimento, que possuem comportamentos próximos, são superiores às telhas metálicas para a redução da carga térmica de radiação. Comparando com os resultados obtidos por MORAES et al. (1999) e CONCEIÇÃO et al. (2008), os dados obtidos foram inferiores, devido às características climáticas diferentes das regiões avaliadas.
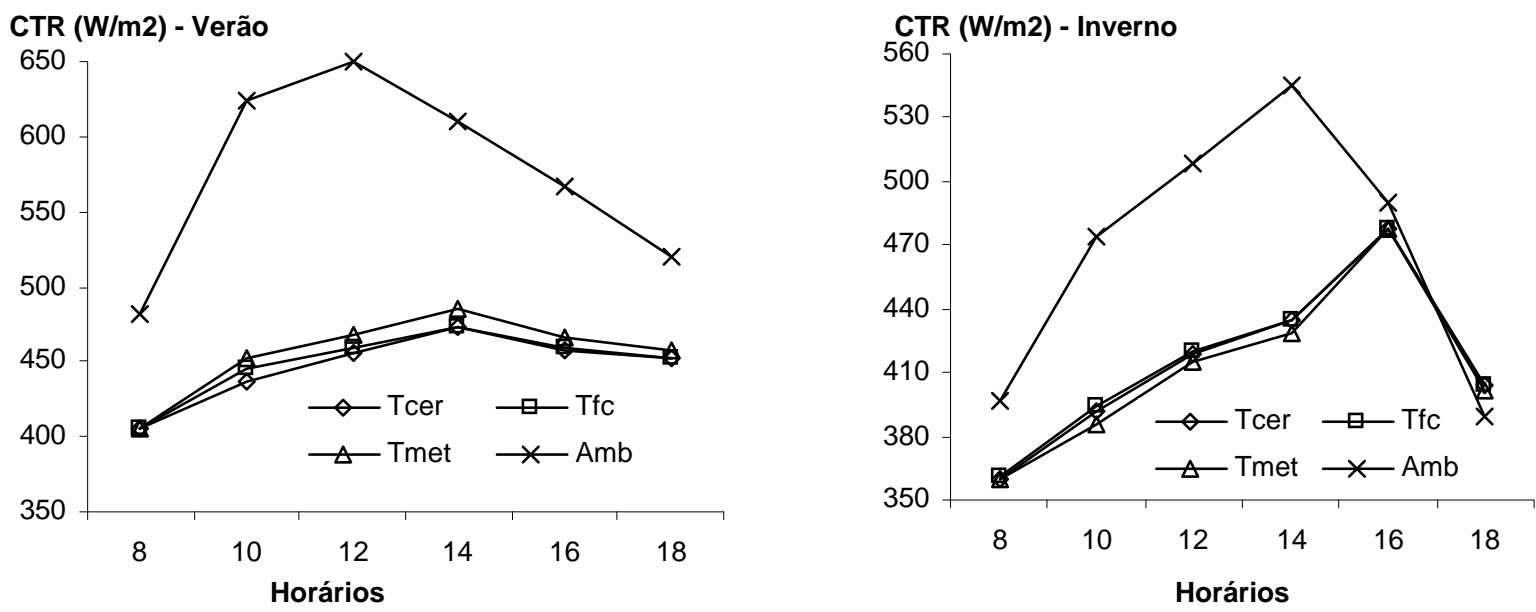

FIGURA 2. Valores médios de CTR para as condições de verão e de inverno, nos ambientes de telhas cerâmicas $\left(\mathrm{T}_{\text {cer. }}\right)$, fibrocimento $\left(\mathrm{T}_{\mathrm{fc}}\right)$ e metálicas $\left(\mathrm{T}_{\text {met. }}\right)$ e na área não sombreada $\left(A_{\text {ext. }}\right)$. Mean values of TLR for summer and winter conditions in the ceramic tile $\left(T_{\text {cer. }}\right)$, cement tile $\left(T_{\text {fc. }}\right)$ and metallic tile $\left(T_{\text {met. }}\right)$ and in the not shaded area $\left(A_{\text {ext. }}\right)$ environments.

\section{CONCLUSÕES}

As telhas cerâmicas e de fibrocimento pintadas de branco na face superior apresentaram comportamentos térmicos semelhantes, com alta eficiência na interceptação da energia solar, sendo as mais indicadas para cobertura de edificações para produção de animais. A telha metálica foi a que mais aqueceu e apresentou o pior desempenho térmico (conforto térmico, inércia térmica e amortecimento térmico). Nas condições de clima em que foram obtidos os dados, verificaram-se condições favoráveis de conforto térmico nas áreas não sombreadas para produção de animais de forma extensiva, principalmente bovinos, manejo comum na região.

\section{REFERÊNCIAS}

BOND, T.E.; KELLY, C.F. The globe thermometer in agricultural research. Transactions of the $A S A E$, St. Joseph, v.36, n.7, p.251-255, 1955.

BUFFINGTON, D.E.; COLLAZO-AROCHO, A.; CANTON, G.H.; PITT, D. Black globe-humidity index (BGHI) as comfort equation for dairy cows. Transation of the ASAE, St. Joseph, v.24, n.3, p.711-714, 1981.

CAMPOS, A. T.; KLOSOWSKI, E.S.; GASPARINO, E.; CAMPOS, A.T. Estudo do potencial de redução da temperatura do ar por meio do sistema de resfriamento adiabático evaporativo na região de Maringá-PR. Acta Scientiarum, Maringá, v.24, n.5, p.1.575-1.581, 2002.

CONCEIÇÃO, M.N.; ALVES, S.P.; TELATIN JÚNIOR, A.; SILVA, I.J.O.; PIEDADE, S.M.S.; SAVASTANO JÚNIOR, H.; TONOLI, G. Desempenho de telhas de escória de alto forno e fibras 
vegetais em protótipos de galpões. Revista Brasileria de Engenharia Agrícola e Ambiental, Campina Grande, v.12, n.5, p.536-539, 2008.

MORAES, S.R.P.; TINÔCO, I.F.; BAÊTA, F.C.; CECON, P.R. Conforto térmico em galpões avícolas, sob coberturas de cimento-amianto e suas diferentes associações. Revista Brasileira de Engenharia Agrícola e Ambiental, Campina Grande, v.3, n.1, p.89-92, 1999.

ROSA, Y.B.C.T. Influência de três materiais de cobertura no índice de conforto térmico, em condições de verão, para Viçosa-MG. 1984. 77 f. Dissertação (Mestrado) - Universidade Federal de Viçosa, Viçosa, 1984.

SANTOS, R.C.; TINÔCO, I.F.; DE PAULO, M.O.; CORDEIRO, M.C.; SILVA, J.N. Análise de coberturas com telhas de barro e alumínio, utilizadas em instalações animais para duas distintas alturas de pé-direito. Revista Brasileira de Engenharia Agrícola e Ambiental, Campina Grande, v.6, n.1, p.142-146, 2002.

THOM, E.C. Cooling degrees - days air conditioning, heating, and ventilating. Transactions of the ASAE, St. Joseph, v.55, n.7, p.65-72, 1958.

TEIXEIRA, V.H. Resfriamento adiabático evaporativo na edificação de maternidade para suínos. 1996. 93 f. Tese (Doutorado) - Faculdade de Ciências Agronômicas, Universidade Estadual Paulista, Jaboticabal, 1996.

TINÔCO, I.F.F. Resfriamento adiabático (evaporativo) na produção de frangos de corte. 1988.92 f. Dissertação (Mestrado) - Universidade Federal de Viçosa, Viçosa, 1988. 